JP3I (Jurnal Pengukuran Psikologi dan Pendidikan Indonesia), 9(2), 2020, 57-67

D0l: http://dx.doi.org/10.15408/p33iv9i2.XXXXX

http://journal.uinjkt.ac.id/index.php/jp3i

\title{
Construct validity of Subjective Well-Being by Confirmatory Factor Analysis (CFA) in Indonesian Caregivers of Intellectually Disabled Children
}

\author{
Risa Dwi Ratnasari ${ }^{1}$, Vuong Truong ${ }^{2}$, Neneng Tati Sumiati ${ }^{3}$ \\ Graduate Institute of Mind, Brain, and Consciousness, Taipei Medical University, Taipei, Taiwan ${ }^{1}$ \\ Brain and Consciousness Research Centre, TMU Shuang Ho Hospital, New Taipei City, Taiwan ${ }^{2}$ \\ Faculty of Psychology, UIN Syarif Hidayatullah Jakarta, Indonesia ${ }^{3}$ \\ risa.wiratnas@gmail.com
}

\begin{abstract}
Bringing up a child with disabilities has particular challenges and demands as these children's disabilities may cause certain impacts on their caregivers' well-being. In most of the studies, caregivers exhibited high scores of negative emotions that led to low subjective well-being. The effort to improve caregivers' wellbeing has been being carried out and one of the ways through subjective well-being research. Diener et al. (2009) define Subjective Well-Being (SWB) as the person's evaluation of their life events in terms of cognitive and affective aspects. The higher rating score of these aspects, the higher level of SWB of the person. The aspects of SWB could be well measured if the instrument has good psychometric properties. The validity of the instruments is crucial to produce good quality research. In the present study, we examined the construct validity of the SWB using Satisfaction with Life Scale (SWLS) and Scale of Positive and Negative Experience (SPANE) scales. The data was collected from 209 parents who had children with intellectual disability in Tangerang and Jakarta. The construct was validated by exploratory factor analysis (EFA) and Confirmatory Factor Analysis (CFA) in the software R version 3.6.2. The EFA results showed that the construct consisted of four factors: one for the cognitive aspect, one for positive affect, and two for negative affects. The CFA results further demonstrated that this model fitted the empirical data.
\end{abstract}

Keywords: Construct validity test, satisfaction with life scale (SWLS), scale of positive and negative experience (SPANE), confirmatory factor analysis (CFA). 


\section{Introduction}

The condition of children with intellectual disability may posit certain challenges for their caregivers. In particular, the dependence of the children to the caregivers has a direct impact on the caregiver's physical and psychological health (Raina\& Donnell, 2005). The survey from the previous study reported that the majority of caregivers of children with intellectual disability (ID) reported negative emotions such as sadness, confusion, worrisome, surprise and so on, which reflect low subjective well-being (Ratnasari \& Suminati, 2017).

The role of caregiver requires their full dedication, and the work burden affects psychologically such high stress, clinical depression and abnormally low subjective well-being (Cummins, 2009). The research of subjective well-being is seeking the factors contributing to enhancing caregiver's subjective well-being (Nikmat et al, 2008). Subjective well-being is essential for people to evaluate their life base on their own values and standard in a positive manner and self-regard to help an individual to create more satisfying lives for themselves and others (Diener et al, 1998).

\section{Subjective Well-Being}

The concept of subjective well-being was originally developed by Edward Diener (Drakulic, 2012). Subjective well-being is a part of well-being that is classified into two categories: objective well-being (OWB) and subjective well-being (SWB). OWB refers to the fulfilment of the external need, which was proposed as eleven criteria, including Nutritional food and clean water, Protective housing A nonhazardous work environment A non-hazardous physical environment, Safe birth control and childbearing, Appropriate health care, A secure childhood, Significant primary relationships, Physical security, Economic security, Appropriate education (Gough, 2003). Meanwhile, SWB refers to the personal perception or subjective appraisal toward the person's life, to what extent the meaning of the good life in their life journey (Desmet \& Pohlmeyer, 2013).

SWB focuses on personal positive evaluation of life. The assessment of subjective well-being evaluation will be different from objective evaluation such as income, equipment, house, etc. The difference in emphasis between "subjective" and "objective" (Veenhoven, Watson, Pichler, \& Wallace, 2010). The formulation of subjective well-being is manifested in the definition of the construct as a person's evaluation of cognitive and affective toward their life. The evaluation encompasses the higher positive emotion and the lower negative emotion associated with individual life satisfaction in reaction to their own experience of life (Diener, Lucas, \& Oishi, 2005).

\section{The Structure of Subjective Well-Being}

According to Diener et al. (2005) definition, the subjective well-being of a person consists of three dimensions, namely, assessment of cognitive aspects, assessment of positive affect and negative affect. The following is a further explanation of these aspects:

\section{Cognitive Dimension}

The cognitive dimension refers to life satisfaction. In this context, life satisfaction directs to the subjective quality of life assessment. The person measures the quality of life based on their subjective criteria (Shin \& Johnson, in Pavot \& Diener, 1993). Initially, people have their criteria to determine the standard of a good life which leads to the judge whether they are satisfied or unsatisfied with their life respectively (Pavot \& Diener, 1993). The evaluation of their life can be measured as the whole component of satisfaction or focus on specific domains. When globally assessed, people generally assess their wellbeing by taking all domains into account. In this concern, life satisfaction can be classified as the global evaluation while the specific domain can be parsed as a happy experience. 


\section{Affective dimension}

Affective dimension reflects emotional evaluation toward various kinds of events of someone's life (Diener et al, 1999). The output of affective evaluation can be seen in the form of mood or emotional judgment to the recent events that they experience. The emotion was manifested in a brief reaction to the specific event or stimuli from the environment, while mood can be manifested such a long term emotional reaction and independently to a specific event.

One perspective viewed that the well-being of Indonesian should regard as the culture and the characteristic of Indonesian people, hence the western instrument of subjective well-being could have bias value (Maulana, Khawaja, \& Obst, 2019). Moreover, the heterogeneity to estimate happiness needs an SWB based assessment of variety in preference to capture the supposed construct (Hoorn, 2018).

Meanwhile, the original version of SWB instrument (SWLS) that has been applied in some countries has a good stable value of psychometric properties with more than .80 Cronbach alpha for reliability. Hence the original version of SWB measurement can be used as a reliable assessment of life satisfaction (Diener et al, 2013; Galanakis et al, 2017; Yin \& Etile, 2019). Global evaluation of the life satisfaction scale has strongly related to the experience of positive emotion and negative emotion which has a causal influence on satisfaction judgment (Schwarz \& Clore, 1983). The original version of the affect scale SPANE also has a good psychometric property with internal consistency more than .80 Cronbach alpha for Italian, Greek, Chinese population. The result of that construct validity revealed, SPANE as a reliable instrument can show useful information about the emotional experience of the person and could be used as an indicator of well-being (Corno et al, 2016; Rahm et al, 2017; Tong \& Wang, 2017).

Construct validity, as a psychometry property is a necessary component of the research instrument, it's the parameter to determine the quality of the scale of certain construct and to see whether the scale is sufficient to measure the intended concept (Kelly \& Vokurka, 1998). In the present study, we examined the original model of subjective well-being measurements from the SWLS and SPANE scales. We expected both of the scales models can be accepted and sufficient to measure subjective well-being as the latent construct.

\section{Instrument Description}

The researcher used two scales to measure subjective well-being. The measurement for cognitive dimension adopted the scaled developed by Diener, Emons, Larsen, Griffin (1985), namely SWLS, containing five items; and affective dimension scale using SPANE (Diener et al., 2010), which consists of 12 items divided into six positive keywords and six negative keywords. The questionnaires for both scales are shown in Table 1.

Table 1. The Cognitive Aspect of Subjective Well-Being Scale

\begin{tabular}{|c|c|c|c|c|c|}
\hline No & Statement & SD & $\mathbf{D}$ & $\mathbf{A}$ & SA \\
\hline 1 & In most ways, my life is close to my ideal. & & & & \\
\hline 2 & The conditions of my life are excellent. & & & & \\
\hline 3 & I am satisfied with my life. & & & & \\
\hline 4 & So far, I have gotten the important things I want in life. & & & & \\
\hline 5 & If I could live my life over, I would change almost nothing. & & & & \\
\hline
\end{tabular}


Next, in the SWB, the affective aspect has specific guidance to fill the scale that should be followed. The instruction and the options of the representative feeling of the experienced event are shown in Table 2.

Please think about what you have been doing and experiencing during the past four weeks. Then report how much you experienced each of the following feelings, using the scale below. For each item, select a number from 1 to 5 , and indicate that number on your response sheet.

Table 2. Affective dimension scale

\begin{tabular}{|c|c|c|c|c|c|}
\hline No & Statement & $\mathbf{N}$ & $\mathbf{S}$ & O & A \\
\hline 1 & Positive & & & & \\
\hline 2 & Negative & & & & \\
\hline 3 & Good & & & & \\
\hline 4 & $\mathrm{Bad}$ & & & & \\
\hline 5 & Pleasant & & & & \\
\hline 6 & Unpleasant & & & & \\
\hline 7 & Happy & & & & \\
\hline 8 & Sad & & & & \\
\hline 9 & Afraid & & & & \\
\hline 10 & Joyful & & & & \\
\hline
\end{tabular}

The scoring method for cognitive scale:

\begin{tabular}{ccccc}
\hline Selection & SA & A & DS & SDS \\
\hline Favorable & 4 & 3 & 2 & 1 \\
Unfavorable & 1 & 2 & 3 & 4 \\
\hline
\end{tabular}

Abbreviation note:

SA: Strongly Agree

DS: Disagree

A: Agree

SDS: Strongly Disagree

The scoring method for Affective scale:

\begin{tabular}{cccccc}
\hline Options & A & O & S & N \\
\hline Favorable & 4 & 3 & 2 & 1 \\
Unfavorable & 1 & 2 & 3 & 4 \\
\hline
\end{tabular}

Abbreviation note:
A: Always
O: Agree
S: Disagree
N: Strongly Disagree 


\section{Method}

Validity test conducted using Exploratory Factor Analysis (EFA) confirmatory factor analysis (CFA) by lavaan package implemented in $\mathrm{R}$ 3.6.2. To process the validity with EFA and CFA, there are some order steps should be followed for all component scales:

\section{Part 1}

Step for EFA:

1. Calculate the matrix of sample correlation from the number of observations in the data set. Plotting the eigenvalues of the sample correlation into a scree plot from the largest to smallest $(1,2, \ldots, p)$ then connecting with the straight line.

2. Setting up a simulated dataset with the number of observations randomly sampled. Calculate the correlation matrix for simulated data and extract the component eigenvalue then arranging from the largest to the smallest position.

3. Repeat step $2 \mathrm{k}$ times (e.g., $\mathrm{k}=1000)$.

4. Calculating the median of the $\mathrm{k}$ eigenvalues at all positions from the previous step, and overlay these medians on the scree plot created in step 1, connecting the points.

5. The crossing of the two lines is the cutoff to determine the number of dimensions present in the data (Kabacoff, 2002)

\section{Part 2}

\section{Step for CFA:}

1. Selecting some factors. The chosen factor should be reasonable and based on the underlying construct or analysis that is the reference factor for further analysis. For grouping, the items into the fit factor, a number factor exploration from the parallel analysis will be used for CFA analysis.

2. Providing the data and fitting the model. The quantitative data will be fitting the model in $\mathrm{R}$ using default options.

3. Estimate a population covariance compared to the observed covariance matrix.

4. Testing the factor loading, which measures the correlation between each item and each modeled factor. Larger values indicate stronger relationships.

5. Evaluating factors through eigenvalues, which has the outcome of total variance explained by each factor. The comparison between eigenvalue to the number of items, and can identify the factors that found the most variability in scores.

6. Evaluating model sufficiency by (Comparative fit index) CFI, (Root mean square residual) RMSR, (Root mean square error of approximation) RMSEA, (Tucker Lewis Index) TLI (Deri et al, 2019; Hooper et al, 2008).

We used EFA as the first step of validating the structure to examine the relevance factor of subjective well-being and to get the initial number of factors according to the analysis of the current data (Albano, 2018). There is no index in EFA to reveal which factor is better, which is the main restriction that would be the part of the next step of the analysis. The next step analysis is CFA, at this part, the result of the analysis model will be shown to verify and test the effectiveness of the model (Suhr, 2006). EFA and CFA are the two stages of a whole process and should be mixed to get a comprehensive construct validity analysis (Anderson \& Gerbing, 1990). 


\section{Results and Discussion}

\section{Results}

The analysis factor showed in this following graph of EFA.

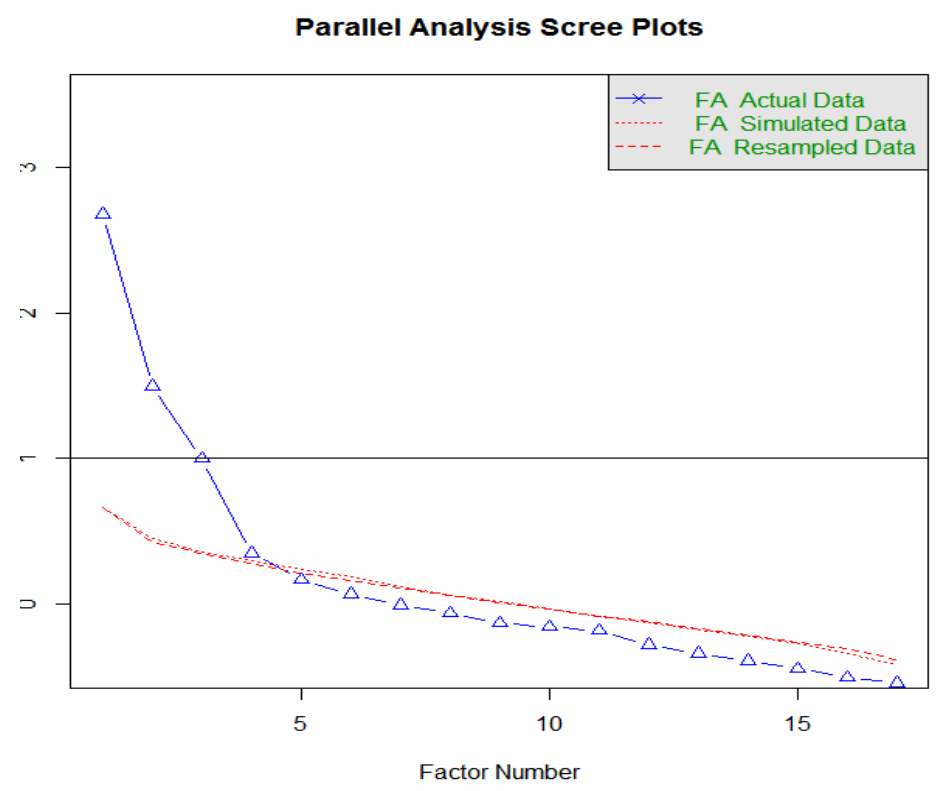

Figure 1. Parallel Analysis Scree Plots

Factor Analysis

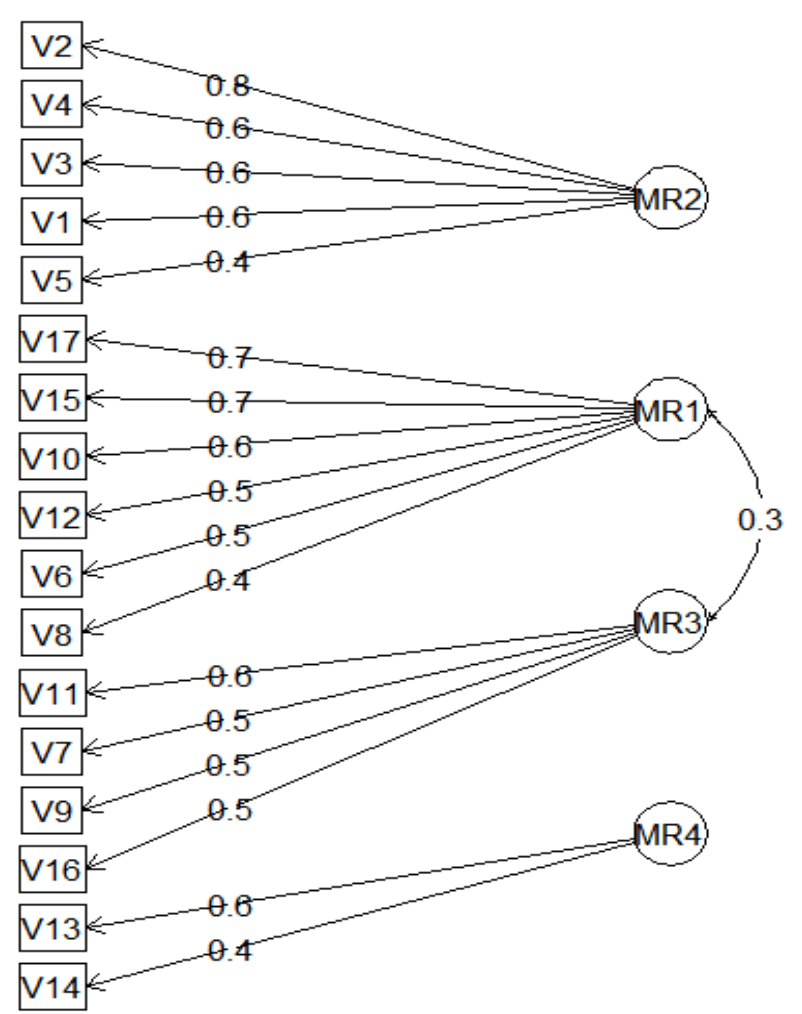

Figure 2. The Result of the Final Factor of SWB by EFA Analysis 
According to the presented parallel analysis scree plots, there is a single blue line showed the observed eigenvalue. The red dotted showed the random eigenvalues or simulated data line. Each point on the line of observed eigenvalue that lies above the corresponding simulated data line is a resulted factor from the analysis or component to extract. In this analysis, we can see 4 factors in the factor analysis "in the beginning, parallel analysis drew over the corresponding simulated data line and 4 components as the suggested factor/principal components.

The root means square of residual (RMSR) from the model is 0.04 . According to the standard, this is still acceptable as the RMSR should be closer to 0. The model has RMSEA (Root Mean Square error of approximation) index 0.067 and range of confidence interval are $0.051-0.083$, while the TLI) of factoring reliability is 0.0812 . The analysis result of the value in those parameters means the model is not good because the ideal number of RMSEA should below 0.05 , and the TLI is good considering it's over 0.9.

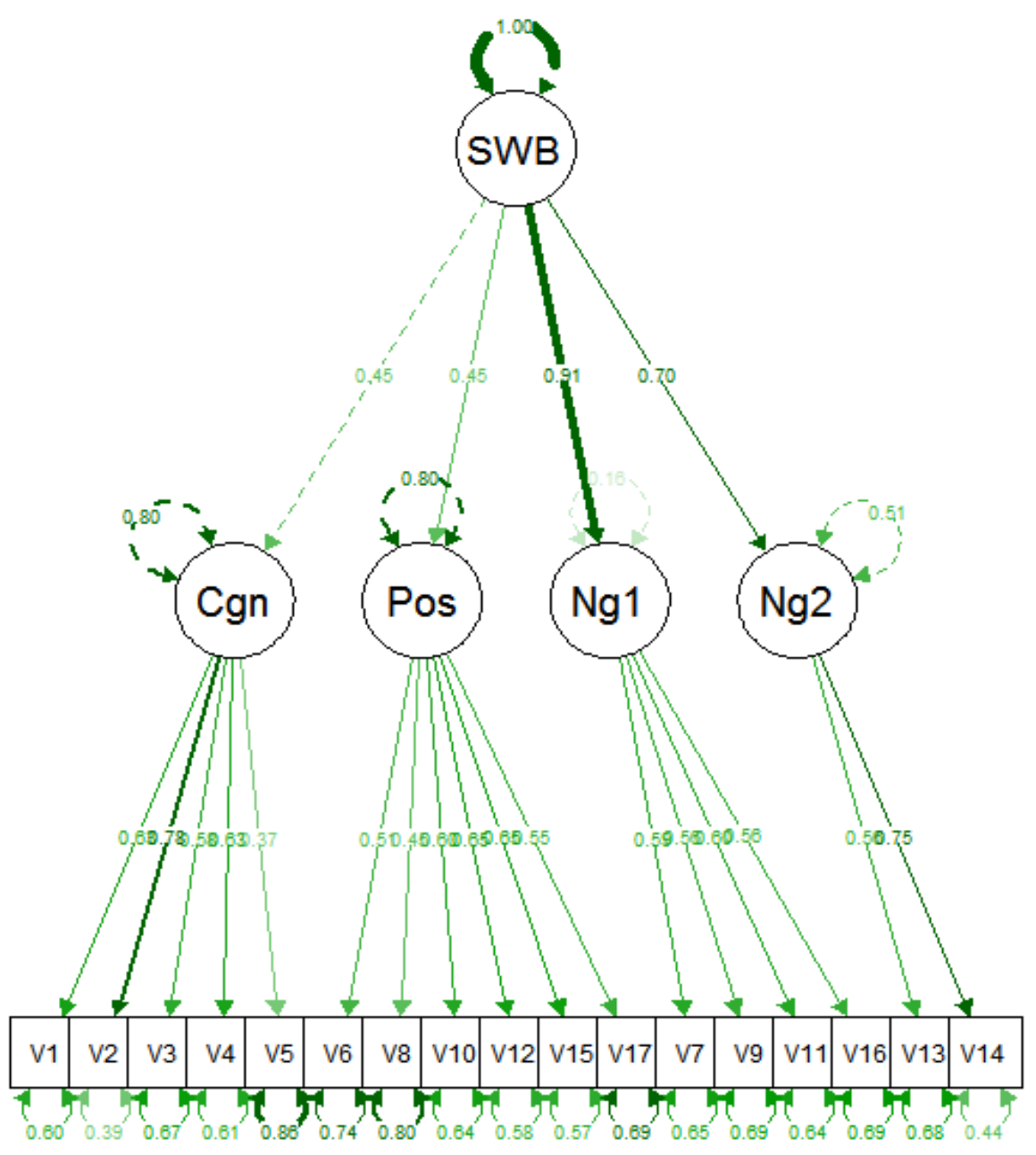

Figure 3. Model CFA before Modification 


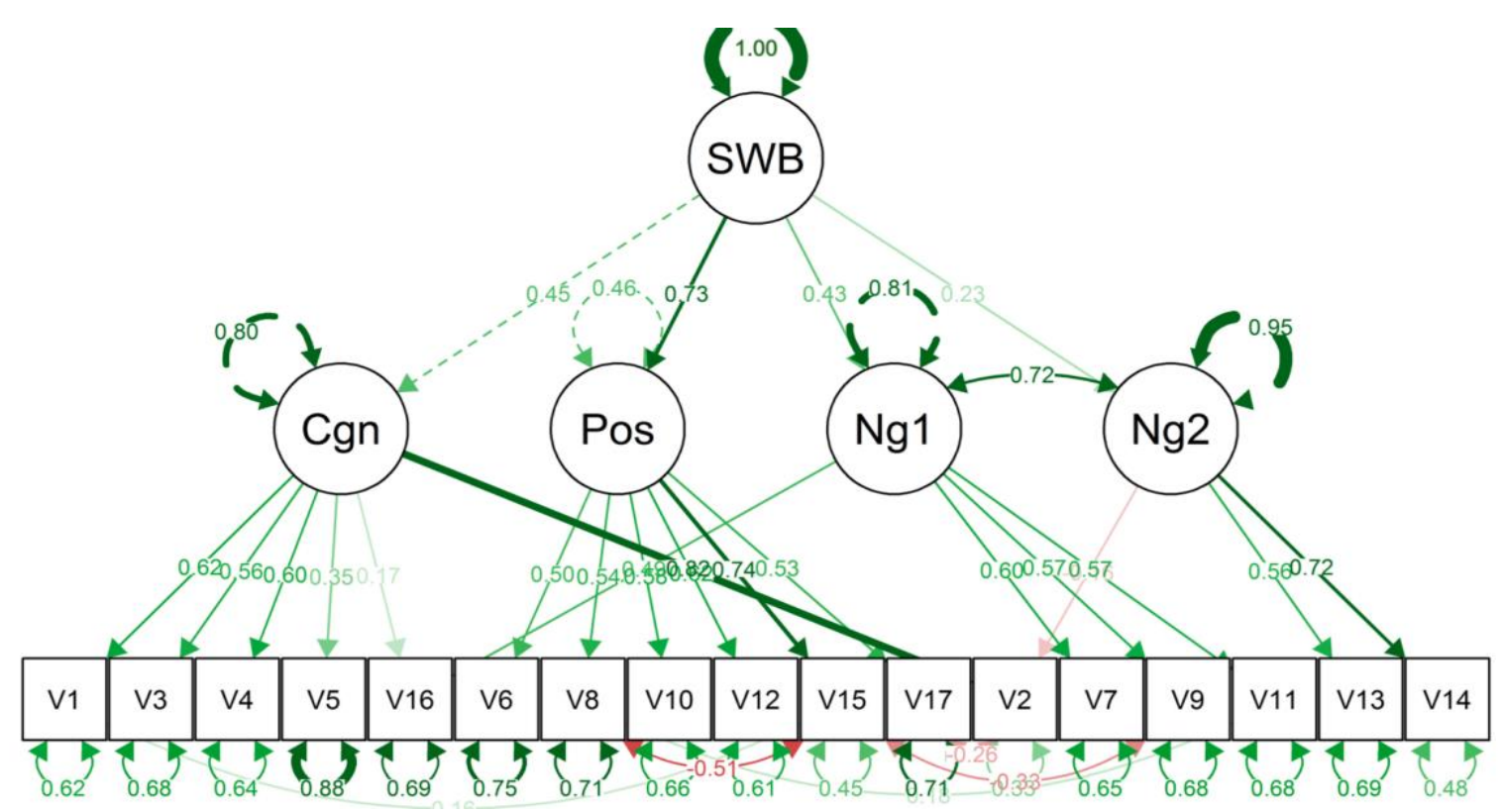

Figure 4. Model CFA after Modification

According to parallel analysis, the construct generates four factors, the label of the factors named following the original construct: MR1 is for cognitive (CGN), MR2 is for positive affective (Pos), MR3 is for negative affective (Ng1) and MR4 is for negative affective (Ng2). After getting the four factors of the construct from Previous analysis, the researcher tested the model fit with second-order analysis, whether each component has a good relation with itself. Then, after getting the fit model of the item, analyzing the relation between the items and the second factor and the second factor with the latent factor.

In other words, all items measured one hidden factor. In the beginning the CFA result was not fit, with CFI $=0.875$, RMSEA $=0.075$, RMSEA ci upper $=0.075$ bic $=7149.004$. Nevertheless, after modifying 8 times, the model fit is found with CFI $=0.928$ RMSEA $=0.048$ RMSEA ci upper $=0.063$ $\mathrm{bic}=7136.733$. The value of RMSEA is $\leq 0.05$, which means all items were only unidimensional.

\section{Discussion}

The result of this validity construct analysis showed that subjective well-being was constructed from 214 subjects generating four factors that we called Cognitive (Cog), Positive affect (Pos), negative affect 1 (Ng1) and Negative affect $2(\mathrm{Ng} 2)$ as in the scree plot. Intriguingly, referring to the original structure of Subjective Well-being, the number of factors in this analysis is different from the number of factors in the primary model that has three factors Cognitive, Positive Affect and Negative Affect. However, the factors in the present analysis are still attributing to the same factor category as the original grouping of the construct.

We evaluated the potential contribution to this model. First, we noticed to the structure of the affection scale that there is a deviant structure of the order of negative affect evaluation. The $\mathrm{Ng} 1$ covered the items 16, 7, 9 and 11 which have the pattern with positive word evaluation between the negative word evaluation. While the $\mathrm{Ng} 2$ is covered items 13 and 14 which have no contrast word between the items. Among the aspects of subjective well-being, positive affect got the higher correlation with the latent factor (SWB) and more stable compare to the negative affect, this result is in line with the previous finding that the dimension with higher variance stability and has the higher correlation with SWB is the positive affect compared to negative affect and satisfaction with life domain (Galinha \& Pais, 2008). Moreover, the 
model showed from all factors, the positive emotion is the greatest aspect of subjective well-being. The condition indicates that in general the caregiver preferred to give high value in the positive affect items and the separation of the factor for the negative effect might be caused by the inconsistency of the rating to the aspect due to the caregivers have difficulty to understand the items or hesitate to assess them self for negative affect experience. The model of this analysis nonetheless is acceptable shown by the model fit metrics.

The result of the analysis revealed the tendency of the caregivers to react positively in evaluating their well-being. This condition is possible to happen because of the positive world view and social support from the environment. Considering the sampling areas were mostly in support group circles that provided social relations with the community which is the fulfillment of basic needs well-being for the Indonesian population (Maulana, 2018).

\section{Conclusion}

This paper attempted to validate the original version of subjective well-being construct with three dimensions (cognitive, positive affect and negative affect) that the assessment we took from the caregiver of children with intellectual disability in Indonesia. Referring to some validation studies show that SWLS for measuring cognitive evaluation of life has good psychometric properties, Likewise SPANE as the measurement for positive and negative affects is also had good psychometric properties across some countries. The EFA and CFA analysis showed the items analysis generated the same factor categories with one addition for negative affect and the model is fit after eight times modification. Positive affect has the biggest factor loading with latent variable compare to negative affect and cognitive dimension, this result is reasonable since positive affect was founded as a higher of variance stability and the highest correlation with subjective well-being in other studies. Therefore, we conclude that the original version of SWB is a good model to be applied in Indonesia but with the concern to participant assistance while filing the scale to avoid misunderstanding of SWB scales.

\section{References}

Albano, A. D. (2018). Introduction to educational and psychological measurement: using R. Retrieved from https://cehs01.unl.edu/aalbano/intro-measurement-r/.

Anderson, J. C. \& Gerbing, D.W. (1990). Structural equation modeling in practice: A review and recommended two-step procedure. Psychology Bulletin, V103:411-423.

Corno G, Molinari G, \& Baños RM. (2016). Assessing positive and negative experiences: validation of a new measure of well-being in an Italian population. Rivista di psichiatria, 51(3):110-115.

Cummins, R. A. (2009). The subjective well-being of people caring for a family member with a severe disability at home: A review. Journal of Intellectual \& Developmental Disability, 26(1), 83-100. https://doi.org/10.1080/13668250020032787.

Dheri, G., Pal, S., Singh, V., Marwaha, S., \& Chodhary, O. (2019). Hands-on training on "statistical tools and database management in agriculture". Icarnahep-caast-snrm department of soil science ( $\mathrm{p}$. 109). Punjab Agricultural University.

Desmet, P. M. A., \& Pohlmeyer, A. E. (2013). Positive design: an introduction to design for subjective well-being. International Journal of Design, 7(3), 5-19.

Ed Diener, Jeffrey J. Sapyta, \& Eunkook Suh. (1998). Subjective well-being is essential to well-being, Psychological Inquiry, 9:1, 33-37. https://doi.org/10.1207/s15327965pli0901_3.

Diener, E., Emmons, R. A., Larsen, R. J., \& Griffin, S. (1985). The Satisfaction with Life Scale. Journal of Personality Assessment, 49, 71-75. 
Diener, E., Lucas, R. E., \& Oishi, S. (2005). Subjective well-being: the science of happiness and life satisfaction. In C. R. Snyder, \& S. J. Lopez (Eds.). Handbook of Positive Psychology (2nd ed., pp. 6373). New York: Oxford University Press.

Diener, Ed, Suh, E., Lucas, R., \& Smith, H. (1999). Subjective well-being: three decades of progress. Psychological Bulletin. 125. 276-302. https://doi.org/10.1037/0033-2909.125.2.276.

Diener, E., Inglehart, R., \& Tay, L. (2013). Theory and validity of life satisfaction scales. Social Indicators Research, 112(3), 497-527. https://doi.org/10.1007/s11205 012-0076-y.

Diener, E., Wirtz, D., Tov, W., Kim-Prieto, C., Choi, D. W., Oishi, S., \& Biswas Diener, R. (2010). New well-being measures: short scales to assess flourishing and positive and negative feelings. Social Indicators Research, 97(2), 143-156. https://doi.org/10.1007/s11205-009-9493-y.

Drakulić, A. M. (2012). A phenomenological perspective on subjective well-being: From myth to science. Psychiatria Danubina, 24(1), 31-37.

Galinha, I. C. C., \& Pais-Ribeiro, J. L. (2008). The structure and stability of subjective well-being: a structure equation modelling analysis. Applied Research in Quality of Life, 3(4), 293314. https://doi.org/10.1007/s11482-009-9063-0.

Galanakis, M., Lakioti, A., Pezirkianidis, C., Karakasidou, E., \& Stalikas, A. (2017). Reliability and validity of the satisfaction with life scale (SWLS) in a Greek sample. The International Journal of Humanities \& Social Studies, 5, 120-127.

Gough, I. (2003). Lists and thresholds: comparing the doyal-gough theory of human need with nussbaum's capabilities approach', wed working paper 01, Wellbeing in Developing Countries ESRC Research Group, University of Bath.

Hoorn, A, Van. (2018). Is the happiness approach to measuring preferences valid? J. Behav. Exp. Econ. 73 (C), 53-65. https://doi.org/10.1016/j.socec.2018.02.002.

Hooper, D., Coughlan, J., \& Mullen, M. R. (2008). Structural equation modeling: Guidelines for determining model fit. Electronic Journal of Business Research Methods, 6(1), 53-60.

Kabacoff, R. I. (2002). Determining the dimensionality of data: A SAS ${ }^{\circledR}$ macro for parallel analysis, Proceedings of the 28th Annual Meeting of SAS Users Group International, Gary, NG: SAS Institute.

Pavot, W., \& Diener, E. (1993). Review of the satisfaction with life scale. Psychological assessment, 5(2), 164-172. https://doi.org/10.1007/s11205-012-0076-y.

Maulana, H., Obst, P., \& Khawaja, N. (2018). Indonesian perspective of well-being: A qualitative study. The Qualitative Report, 23, 3136 - 3152.

Maulana, Herdiyan, Khawaja, Nigar., \& Obst, Patricia. (2019). Development and validation of the Indonesian well-being scale. Asian Journal of Social Psychology 22, 268-280. https://doi.org/ 10.1111/ajsp.12366.

Nikmat, A. W., Ahmad, M., Oon, N., \& Razali, S. (2008). Stress and psychological wellbeing among parents of children with autism spectrum disorder. ASEAN Journal of Psychiatry, 9(2), 65-72.

O'Leary-Kelly, S.W., Vokurka, R.J., (1998). The empirical assessment of construct validity. Journal of Operations Management 16 (4), 387-405.

Rahm, T., Heise, E., \& Schuldt, M. (2017). Measuring the frequency of emotions-validation of the scale of positive and negative experience (SPANE) in Germany. PLoS ONE, 12, e071288. https://doi.org/10.1371/journal.pone.0171288.

Raina, P., O'Donnell, M., Rosenbaum, P., Brehaut, J., Walter, S. D., Russell, D., \& Wood, E. (2005). The health and well-being of caregivers of children with cerebral palsy. Pediatrics, 115(6), 626-636. https://doi.org/10.1542/peds.2004-1689.

Ratnasari, R. D., \& Sumiati, N. T. (2017). Pengaruh self-compassion, religiusitas, support group dan pendapatan terhadap subjective well-being orang tua anak tunagrahita. JP3I, 1(1), 63-77. 
Schwarz, N., \& Clore, G. L. (1983). Mood, misattribution, and judgments of well-being: Informative and directive functions of affective states. Journal of Personality and Social Psychology, 45, 513-523.

Suhr, D. D. (2006). Exploratory or confirmatory factor analysis? Statistics and Data Analysis, 31, Retrieved April 20, 2012.

Tong, K. K., \& Wang, Y. Y. (2017). Validation of the Flourishing Scale and Scale of Positive and Negative Experience in a Chinese community sample. PLoS ONE, 12. https://doi.org/10.1371/ journal.pone.0181616.

Watson, D., Pichler, F., \& Wallace, C. (2010). Subjective well-being in Europe. Luxembourg: Office for Official Publications of the European Communities.

Yin, R., \& Etilé, F. (2019). Measuring identity orientations for understanding preferences: A French validation of the Aspects-of-Identity Questionnaire, Retrieved from https://halshs.archivesouvertes.fr/halshs02057130/document. 